\section{Recognition time for information stored in long-term memory}

\author{
J. F. JUOLA, I. FISCHLER, C. T. WOOD, and R. C. ATKINSON \\ Stanford University, Stanford, California 94305
}

Two experiments were performed to determine the effects of number of words in a target set (varying from 10 to 26) and the nature of distractor words on the latency of both positive and negative recognition responses. Before the test phase, $\mathrm{S}$ memorized a list of words and then was tested with a series of single words. To each presentation $\mathbf{S}$ made a positive or negative response to indicate whether or not the word was a member of the memorized target list. Response latency was observed to be an increasing function of memory list length. Negative response latency also was greater if distractor words were visually or semantically similar to specific target words. The results were analyzed in terms of a modified signal detection model. It is assumed that $\mathrm{S}$ makes a subjective judgment of the familiarity of a test item and on that basis decides either to respond immediately or to delay the response until a search of the memorized list can be executed. Several different models of the search process are considered and evaluated against latency measures and error data.

Proposed mechanisms for the method by which information is retrieved from memory have often included a search process as a part of the act of retrieval. Yntema and Trask (1963), for example, have been successful in applying search models to tasks involving recall of information from memory. In studying short-term recognition memory, Sternberg (1966) has shown that a serial and exhaustive search, or scan, of a target set may take place when $\mathbf{S}$ makes a decision about whether or not a given test digit is a member of the memorized set. This scanning process was inferred from the fact that both positive and negative decision latencies were linear increasing functions of the size of the target set with equal slopes.

Although a search process has been assumed to occur during both recognition and recall, it has been suggested that the type of search may be quite different in these two cases (Atkinson \& Shiffrin, 1968; Shiffrin \& Atkinson, 1969). A recall test might initiate a serial search of many memory locations, whereas a recognition test might result in a memory search which interrogates only a single storage location. Sternberg's (1966) study provides no evidence in favor of this type of limited search in a short-term recognition task; however, his proposed scanning mechanism is an unlikely representation of the search processes involved in long-term memory.

One way to investigate the recognition process in long-term memory is to employ Sternberg's paradigm, using very long lists of previously memorized items as the target set. Under these conditions $S$ could not maintain the complete target set in short-term memory and would have to rely on long-term processes. Experiment 1 employs this procedure where the size of the target set ranges from 10 to 26 items. If the latency of positive and negative recognition responses is a function of set size, as it is in short-term memory, then a serial search process could be posited as part of long-term retrieval. If recognition latency is independent of set size (as might be expected if memory was strictly "content addressable"), then a search process which interrogates only a single storage location could be assumed; i.e., $\mathrm{S}$ would be able to make a decision based on the retrieved contents of the memory location assigned to the tested stimulus.

In Experiment 2 all Ss memorized a target list of 16 words. The similarities of some distractor words to words in the target lists were manipulated by presenting homophones and synonyms of target words. Other distractors were unrelated to target words and were either shown only once during the session or were repeated several times. The aim of the second experiment was to study how positive and negative recognition latencies would be influenced by the acoustic and semantic similarity of distractor items to target items and also to investigate the effect of repeated presentations of distractor items.

\section{EXPERIMENT 1}

A study by Wingfield and Branca (1970), using the Sternberg procedure and relatively large target sets (up to 12 items), has shown that an increasing number of errors is made as the target set exceeds the span of immediate memory. In order to avoid having to correct latency data for guessing, it is necessary that the rate of incorrect responses be uniformly low.
This can be done by using a list of unambiguous items, such as common words, as the target set and requiring $S$ to memorize the set to a high level of mastery. In the first study each $S$ memorized a list of 10,18 , or 26 words before the experimental session. With this list as the target set, a long series of words was presented, and to each presentation $\mathbf{S}$ gave either $a$ positive or negative recognition response.

\section{Method}

The Ss were 30 right-handed female undergraduates from Stanford University. Each $S$ was assigned randomly to one of three list-length conditions $(10,18$, or 26 words).

A set of 100 words was selected from the list of 925 nouns provided by Paivio, Yuille, and Madigan (1968) on the basis of three criteria: (1) The words occurred with high frequency in English [Categories A or AA according to the Thorndike and Lorge (1944) classification ]; (2) they were three to five letters in length; (3) all were one syllable. Each word was typed in capital letters on a $5 \times 8$ in. index card with an IBM Registry typewriter.

In constructing the target lists for individual Ss, the 100 words were ordered randomly, and successive blocks of 10,18 , or 26 words were selected until each word had been used in at least one list. This process was repeated to generate 30 different lists. The set of 52 distractor words to accompany each list was selected randomly from the words remaining in the pool after the target words had been removed.

During testing, each word was shown singly, using an Iconix tachistoscope and exposure box (System 153). The visual area exposed to $S$ measured $7 \times 3 \frac{1}{2}$ in., and the viewing distance was about $2 \mathrm{ft}$. The words appeared in the lower center of the visual area and subtended a horizontal visual angle of less than $2.0 \mathrm{deg}$. Between stimulus exposures the display field was dark except for a small circle of light $(1.4 \mathrm{fL})$ near the center of the field. The display brightness averaged $39 \mathrm{fL}$, with the word appearing immediately below the central circle.

On a low table to the right of $S$, three telegraph keys were arranged along an arc, with each key separated from the adjacent key by $3 \mathrm{~cm}$. The $\mathrm{S}$ could comfortably rest her right forefinger on the center key between trials and could make a short, natural movement to the right or left to strike either of the two response keys. One-half of the Ss in each group were selected randomly to depress the right key when a target word was presented (positive recognition response) and to 


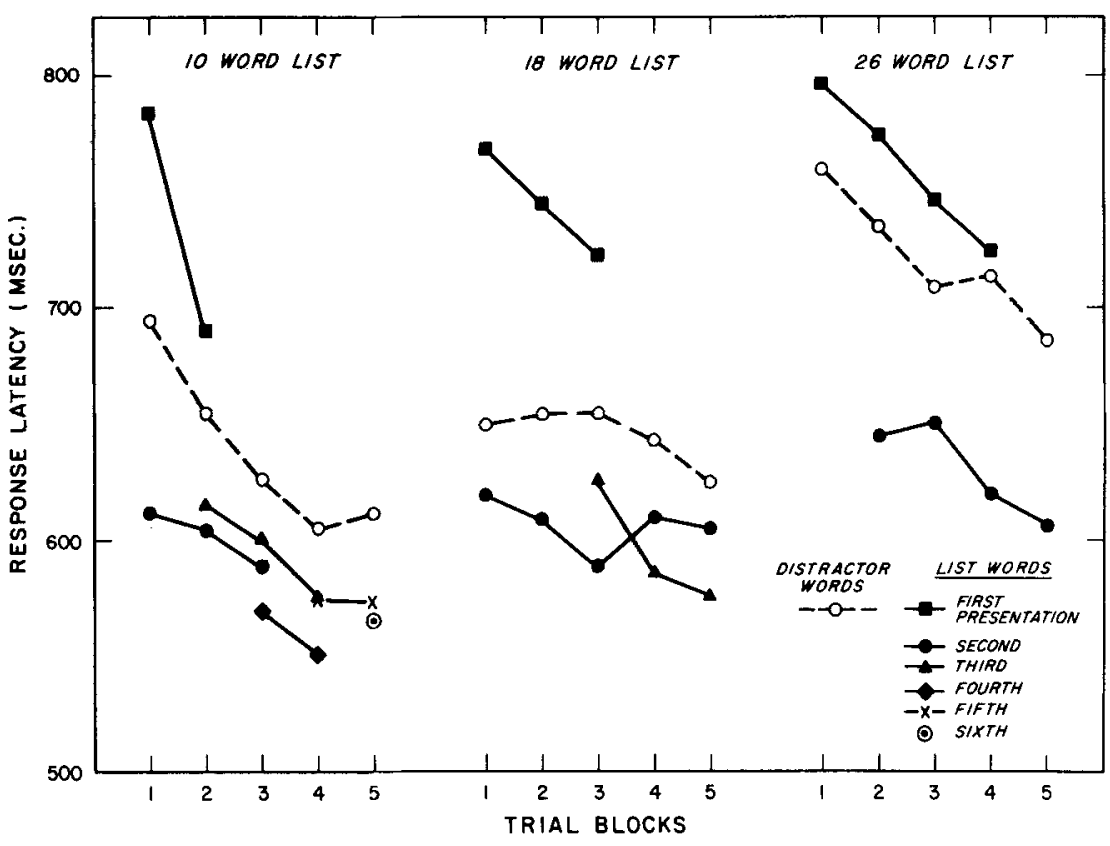

Fig. 1. Group mean response latency as a function of trial block number and type of test.

depress the left key when the presented word was not in the list (negative recognition response). These conditions were reversed for the other Ss. A button held by $\mathbf{S}$ in the left hand was used to initiate each word exposure.

The Ss were contacted approximately $24 \mathrm{~h}$ before the experimental session and given a list of words to memorize. The Ss were instructed to read through the list repeatedly, attempting to recall the words in their correct serial order after each reading. They were asked to spend approximately $1 / 2 h$ on this task, or until one successful complete recall could be made.

At the start of the experimental session, $S$ was handed a list of the target words typed in a style identical to that used on the $5 \times 8$ in. stimulus cards. The $S$ was allowed to study the list for $3 \mathrm{~min}$ and then was given a sheet of paper and instructed to write the list of words in their correct serial order. After writing the words, the original list was again given to $\mathrm{S}$ to study, and after a 3-min interval another written test was administered. All 30 Ss satisfied the preexperimental criterion by recalling their lists in correct serial order on both written tests.

The $S$ was then seated at the tachistoscope and was told that the following sequence of events would occur on each trial: (1) E would place a card with a word typed on it into the tachistoscope. (2) E would say a single two-digit number. (3) $S$ would repeat this number and begin counting backwards by ones (this procedure was undertaken to prevent $\mathrm{S}$ from actively rehearsing the target words before the stimulus exposure). (4) After counting backwards at least two numbers, $S$ could press the button in her left hand. (5) One-half second later the display would be illuminated for $1 / 2$ sec. (6) $\mathrm{S}$ would then make a positive or negative response by depressing the appropriate key. Errors were very infrequent, but when they occurred $\mathrm{S}$ was immediately told that his response was incorrect. (7) After an interval of approximately $10 \mathrm{sec}$, the next trial began.

To insure that $\mathrm{S}$ was familiar with the procedure, eight practice trials were run, using the digits $1-8$ presented in a random order. The $S$ was instructed to make a positive response if a digit from 1 to 4 appeared and a negative response otherwise. After the practice trials $\tilde{\mathbf{S}}$ was given the list of target words to read through once more before the test trials began. Next, $E$ reminded $S$ to respond as rapidly as possible on each trial while being careful to avoid incorrect responses, and then the first trial began.

The test session consisted of 104 trials, half positive and half negative. For Ss with lists of length 10, each target word occurred four, five, or six times during the session. Words in the 18-word lists occurred two or three times each, whereas every word in the 26-word lists was presented exactly twice. Distractors were never repeated; i.e., 52 different nonlist words were shown. All words were ordered randomly within the test series, with the single constraint that no more than eight target or distractor words could occur in succession. The test session averaged $35 \mathrm{~min}$.

\section{Results}

The latencies of all responses were recorded. The data for correct recognition responses were grouped into five trial blocks, and a median latency was obtained for each $\mathrm{S}$ for negative responses. Positive responses were grouped into different classifications, depending on the number of times the target word had been presented previously during the session, and median latencies were also obtained for each S. For each list length, group mean latencies were obtained by averaging medians for individual Ss; these are plotted in Fig. 1. ${ }^{1}$ Each of the first four blocks in Fig. 1 contains 21 trials, whereas the fifth block consists of the final 20 trials in the session. In almost every case, latency is observed to be a decreasing function of the trial block number. It is clear, however, that most of the differences among latencies to target words are due to the fact that the very first response to a target word tends to be extremely slow. Thereafter, positive responses are more rapid than negative ones, and over subsequent tests differences among positive responses are relatively small.

Table 1 summarizes the data presented in Fig. 1, showing latency for (1) initial tests of target words, (2) all subsequent tests of target words combined, and (3) all tests of Table 1

Latency, Standard Deviation, and Percent Errors for Positive and Negative Responses

\begin{tabular}{|c|c|c|c|c|}
\hline \multirow[b]{2}{*}{$\begin{array}{c}\text { List } \\
\text { Length }\end{array}$} & & \multicolumn{2}{|c|}{ Positives } & \multirow[b]{2}{*}{ Negatives } \\
\hline & & $\begin{array}{l}\text { First } \\
\text { Test }\end{array}$ & $\begin{array}{c}\text { Subsequent } \\
\text { Tests } \\
\end{array}$ & \\
\hline 10 & $\begin{array}{l}\text { Latency } \\
\text { SD } \\
\text { Percent Errors }\end{array}$ & $\begin{array}{c}753 \\
188 \\
14.8\end{array}$ & $\begin{array}{c}579 \\
82 \\
1.9\end{array}$ & $\begin{array}{r}627 \\
107 \\
1.5\end{array}$ \\
\hline 18 & $\begin{array}{l}\text { Latency } \\
\text { SD } \\
\text { Percent Errors }\end{array}$ & $\begin{array}{l}721 \\
176 \\
13.8\end{array}$ & $\begin{array}{c}591 \\
97 \\
0.9\end{array}$ & $\begin{array}{r}648 \\
101 \\
1.2\end{array}$ \\
\hline 26 & $\begin{array}{l}\text { Latency } \\
\text { SD } \\
\text { Percent Errors }\end{array}$ & $\begin{array}{c}756 \\
176 \\
8.7\end{array}$ & $\begin{array}{c}623 \\
97 \\
1.3\end{array}$ & $\begin{array}{r}719 \\
134 \\
0.9\end{array}$ \\
\hline
\end{tabular}




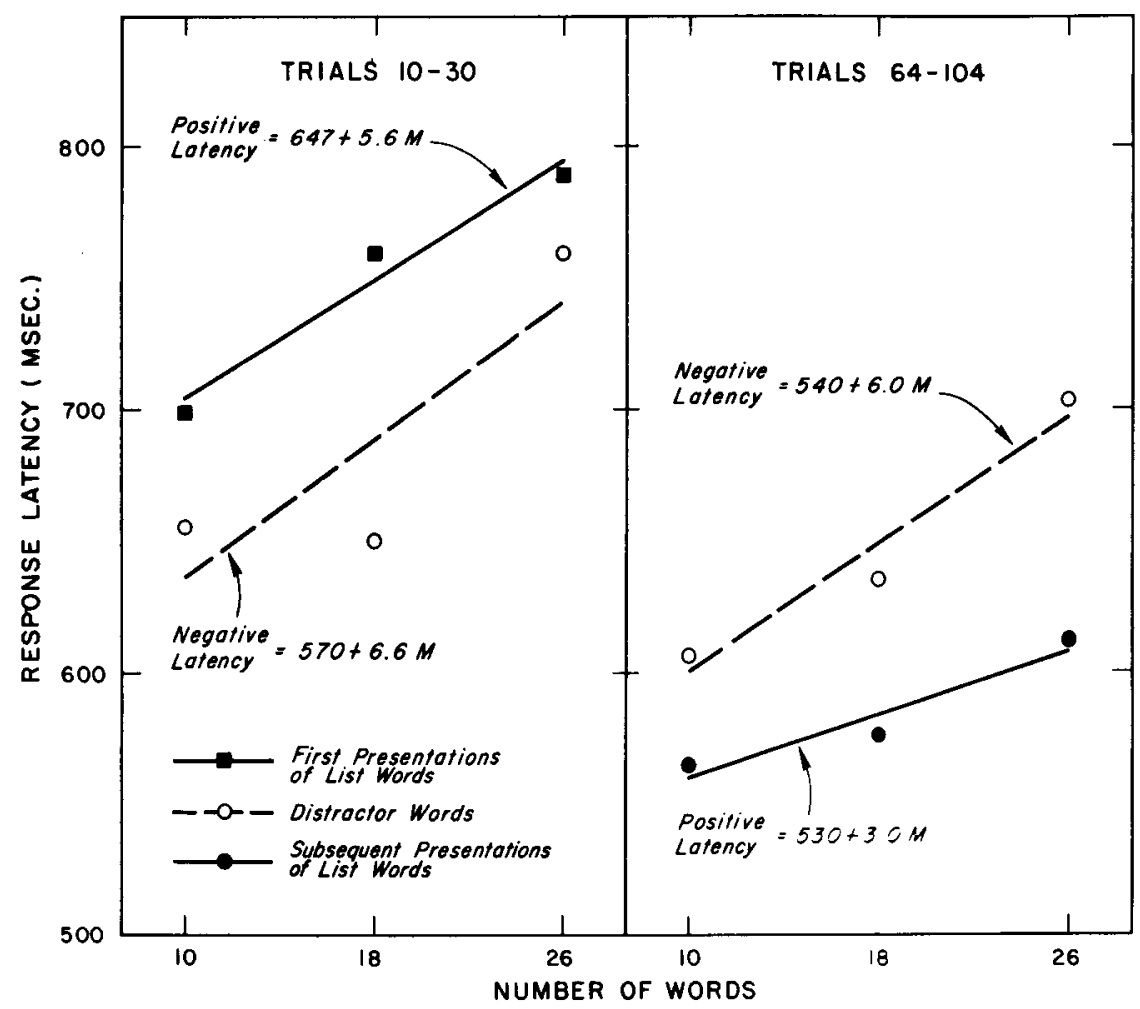

Fig. 2. Mean response latency as a function of target list length for initial presentations of target words and for distractor words in Trials 10-30 (left panel) and for distractor words and subsequent presentations of target words in Trials 64-104 (right panel).

distractor words. As in Fig. 1, data are for correct responses only and represent group means of the median response latencies for each $\mathrm{S}$. Table 1 also presents the mean standard deviation (based on the within-S variance for each trial type) and percent errors for the various response classifications. The overall error rate was $2.7 \%$, but an inspection of Table 1 indicates that most of these errors occurred on initial presentations of target words. None of the observed differences in error rates among the three experimental groups were statistically significant.

Comparisons of latency differences between groups should take into account effects due to test position within the session, since, as shown in Fig. 1, latency decreases over trial blocks. In order to evaluate group differences, it is necessary to control for average test position. This was done for initial presentations of target words by using the data from Trials 10-30 only, since the first trials in the session contribute a disproportionate number of observations to the 10 -word group and the later trials include many tests of items in the 26-word group. For Trials $10-30$ the mean test positions for the first presentation of a target item were $18.8,19.7$, and 19.9 for lists of 10,18 , and 26 words, respectively. linear functions relating latency to target set size were obtained by the method of least squares. Separate Kruskal-Wallis tests showed the differences between the latencies for the three list-length groups to be significant for both positive responses $(\mathrm{H}=6.2, \mathrm{df}=2, \mathrm{p}<.05)$ and negative responses $(H=10.1, \mathrm{df}=2, \mathrm{p}<.01)$.

The right panel of Fig. 2 presents data for the last two trial blocks (Trials 64-104) for negative responses and positive responses, excluding trials on which a target word was presented for the first time. Again, linear functions were fit to the data by the method of least squares. Kruskal-Wallis tests showed the differences between the latencies for the three list-length groups to be significant for negative responses $(\mathrm{H}=9.7, \mathrm{df}=2, \mathrm{p}<.01)$ but not for positive responses $(\mathrm{H}=4.8, \mathrm{df}=2, \mathrm{p}<.10)$.

Latency as a function of serial position of the target items in the study list was obtained for each list-length group for initial tests of target words, for all subsequent tests, and for all tests combined. In every case there was absolutely no trend relating response latency to serial position of the target word.

Latency as a function of the number of intervening items since the last test of a given target word is shown in Fig. 3. All three groups show an increasing trend in response latency as the lag between consecutive tests of the same target word increases. If this lag is short, all three groups show about the same response latency. For distractor items in Trials 10-30 are latency of negative responses to shown in the left panel of Fig. 2. The

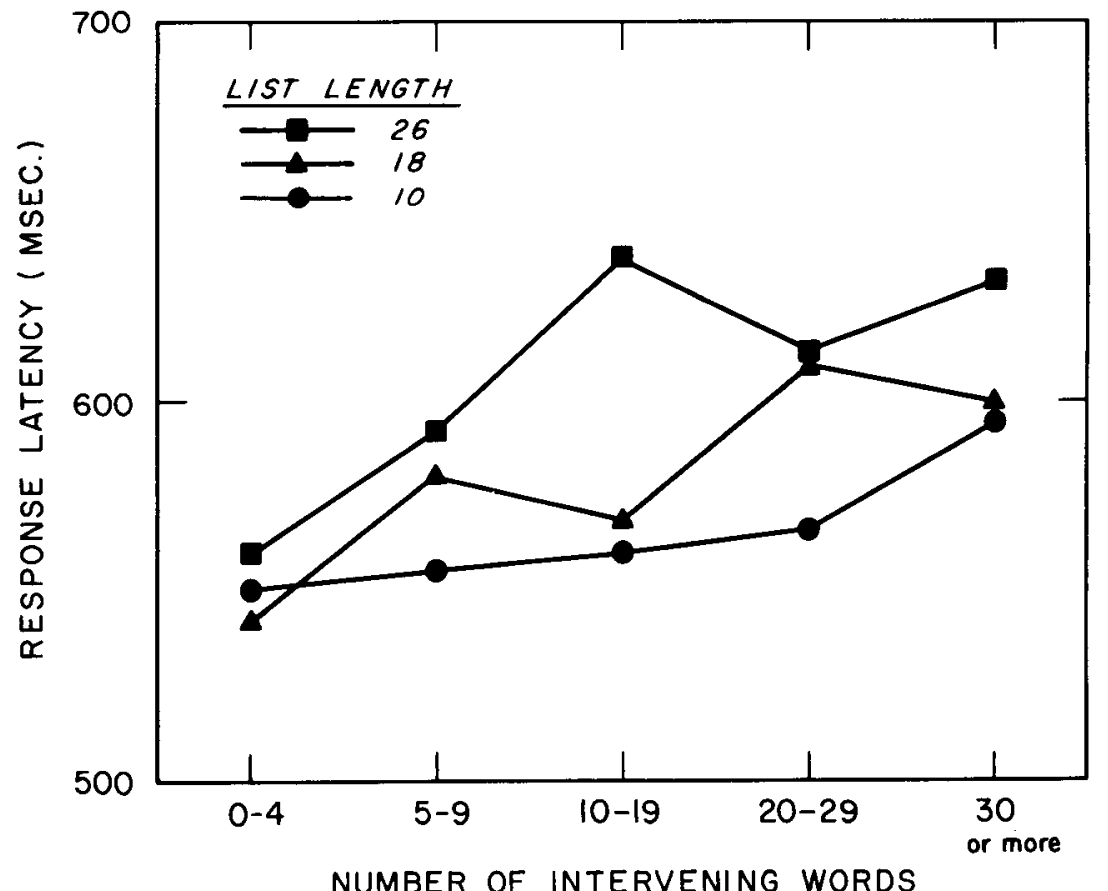

Fig. 3. Mean positive response latency as a function of the number of intervening words between consecutive presentations of a target item. 


\begin{tabular}{|c|c|c|c|c|c|c|c|c|}
\hline & & \multicolumn{3}{|c|}{ Targets } & \multicolumn{4}{|c|}{ Distractors } \\
\hline & & $\begin{array}{l}\text { First } \\
\text { Test }\end{array}$ & $\begin{array}{l}\text { Second } \\
\text { Test }\end{array}$ & $\begin{array}{c}\text { Third } \\
\text { Test }\end{array}$ & Homophones & Synonyms & $\begin{array}{l}\text { Repeated } \\
\text { Neutrals }\end{array}$ & $\begin{array}{l}\text { Unrepeated } \\
\text { Neutrals }\end{array}$ \\
\hline Day 1 & $\begin{array}{l}\text { Latency } \\
\text { Percent Errors }\end{array}$ & $\begin{array}{r}804 \\
22.0\end{array}$ & $\begin{array}{r}659 \\
0.0\end{array}$ & $\begin{array}{r}653 \\
2.0\end{array}$ & $\begin{array}{r}893 \\
5.3\end{array}$ & $\begin{array}{r}738 \\
4.9\end{array}$ & $\begin{array}{r}725 \\
2.0\end{array}$ & $\begin{array}{r}713 \\
0.0\end{array}$ \\
\hline Day 2 & $\begin{array}{l}\text { Latency } \\
\text { Percent Errors }\end{array}$ & $\begin{array}{l}653 \\
10.7\end{array}$ & $\begin{array}{r}580 \\
1.8\end{array}$ & $\begin{array}{r}576 \\
1.3\end{array}$ & $\begin{array}{r}784 \\
5.7\end{array}$ & $\begin{array}{r}708 \\
3.8\end{array}$ & $\begin{array}{r}644 \\
2.5\end{array}$ & $\begin{array}{r}641 \\
0.0\end{array}$ \\
\hline Overall & $\begin{array}{l}\text { Latency } \\
\text { Percent Errors }\end{array}$ & $\begin{array}{r}733 \\
16.4\end{array}$ & $\begin{array}{r}622 \\
0.9\end{array}$ & $\begin{array}{r}617 \\
1.6\end{array}$ & $\begin{array}{r}793 \\
5.5\end{array}$ & $\begin{array}{r}731 \\
4.3\end{array}$ & $\begin{array}{r}682 \\
2.3\end{array}$ & $\begin{array}{r}673 \\
0.0\end{array}$ \\
\hline
\end{tabular}

lags of 10 or more, however, latency appears to be an increasing function of list length $(\mathrm{H}=6.9, \mathrm{df}=2, \mathrm{p}<.05)$.

\section{EXPERIMENT 2}

Experiment 1 demonstrated that such variables as the number of times a target word is presented as well as the lag between consecutive tests have a large effect on the latency of a positive response. A second experiment was designed to measure the effects of several manipulations of word familiarity on negative response latencies. Specifically, distractor words were presented that were either semantically or acoustically similar to words in the target list. Other distractors were neutral words that either were shown only once or were presented several times during the session.

\section{Method}

In Experiment 2 a list of 16 pairs of nouns was used; 8 were synonym pairs and 8 were homophone pairs. ${ }^{2}$ Fifteen right-handed female undergraduates from Stanford University were used as Ss, each receiving a target list made up of a random combination of one word from each pair. The procedure was the same as in Experiment 1, with the exception that Ss were run for two 96-trial sessions on consecutive days.

During an experimental session, each target word was presented three times to yield a total of 48 positive trials. An equal number of negative trials occurred, involving four types of distractor words: (1) the 8 homophones of words in the target list, (2) the 8 synonyms of words in the target list, (3) 17 neutral words that were presented once each, and (4) 5 neutral words that were presented three times each. Each $\mathrm{S}$ was presented with a different set of neutral distractor words in Sessions 1 and 2. The neutral words were balanced with respect to number of letters (three to five), number of syllables (one), and Thorndike-Lorge frequency with words in the homophone and synonym pairs.

Each $\mathrm{S}$ received a different random sequence of test items. For repeated words there is the obvious limitation that the first presentations tend to occur early in the session and the third presentations tend to occur late. The test sequences were, therefore, constrained so that within Trials $25-86$ the mean test positions for all seven types of trials were approximately equal. All first presentations of repeated distractors occurred in the initial 25 trials.

\section{Results}

Latencies for correct responses are presented in Table 2. A median reaction time for each of the seven types of trials was obtained for Sessions 1 and 2 separately, and for the combined data for both days. Table 2 presents the mean latency across median values for each of $15 \mathrm{Ss}$ along with the error rates for the various types of trials. The data presented here are from Trials 25-86 only.

The results show the same pattern as in Experiment 1, with response latency being much faster for the second and third tests of target words than for the initial presentations. This is true for the data for both sessions as well as for the combined data. The difference between mean latencies for responses to the second and third presentations of target words on each day was not significant. As in Experiment 1, the negative response latency to neutral distractor words was less than the latency of responses to initial presentations of target words but was greater than that of subsequent tests (13 of 15 Ss showed this ordering of median response latencies in Session 1 and 11 of 15 in Session 2).

As expected, negative response latency to synonyms of target words was greater (for 12 of $15 \mathrm{Ss}$ ) than the response latency to neutral distractors. Somewhat surprisingly, the latency to homophones was even greater than that of responses to synonyms. After the data had been collected, a closer look at the homophone pairs revealed that they could be divided into two classifications: those which are spelled nearly alike (and therefore are visually quite similar) and those which have quite different spellings. ${ }^{3}$ In the combined data the mean response latency to homophone distractors that were classified as visually similar to their respective target-word pairs was 895 msec, whereas latency to those that were classified as visually dissimilar was $716 \mathrm{msec}$. The latency measure for the visually dissimilar homophones is not significantly different from the latency measure of $673 \mathrm{msec}$ for unrepeated neutral distractors.

Unlike the large latency effect due to the repetition of target words, there was no significant difference between latencies to repeated neutral distractors and to unrepeated neutrals. This is true as well for both the second and third presentations of repeated distractors separately, when their latencies are compared with those of unrepeated neutrals. The effect on response latency of repeating target words was shown to decrease as a function of the lag between repetitions in Experiment 1. It might be expected, then, that if there is any effect at all of repeating distractor words, it should be greatest at short lags. For short lags $(0.9$ intervening words) the mean negative latency for repeated distractors in Experiment 2 was $701 \mathrm{msec}$. For intermediate lags (10-19 intervening words) the latency was $698 \mathrm{msec}$, and for long lags ( 20 or more intervening words) the latency was $680 \mathrm{msec}$. Negative response latency thus appears to be an inverse function of the lag between successive repetitions of distractor words; note, however, that the size of the effect is not substantial and that only 10 of 15 Ss showed the trend.

\section{DISCUSSION}

It has been suggested by Kintsch (1967) that Ss subjectively judge the familiarity of an item on a recognition test and can use this measure in making a decision about whether or not the item had been presented earlier. For the present paper, the model described by Kintsch has been modified somewhat to account for the results obtained in our experiments.

A schematic representation of the model is shown in Fig. 4. It is assumed that each presented word has 


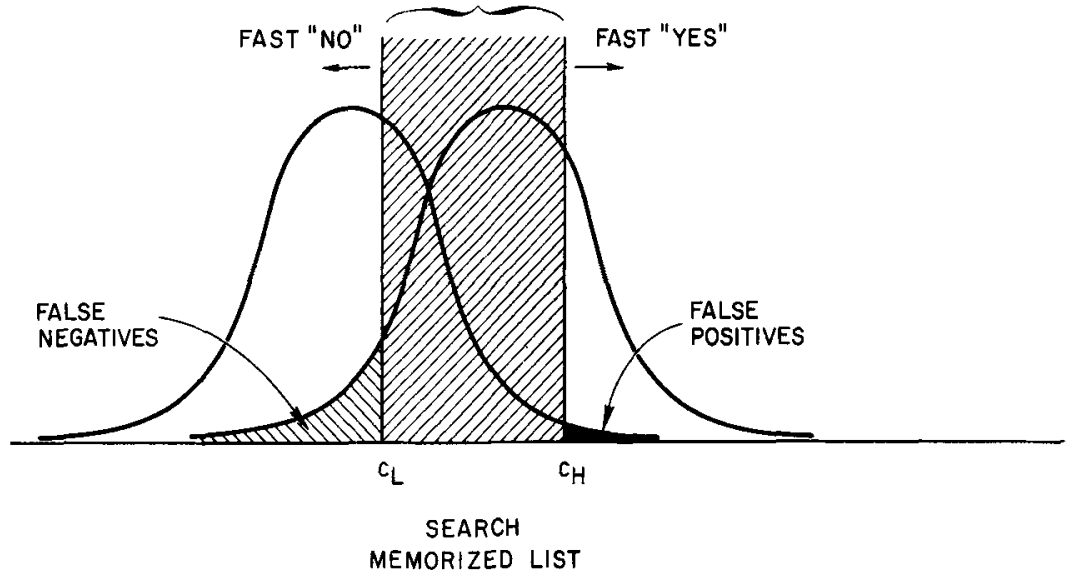

(B)

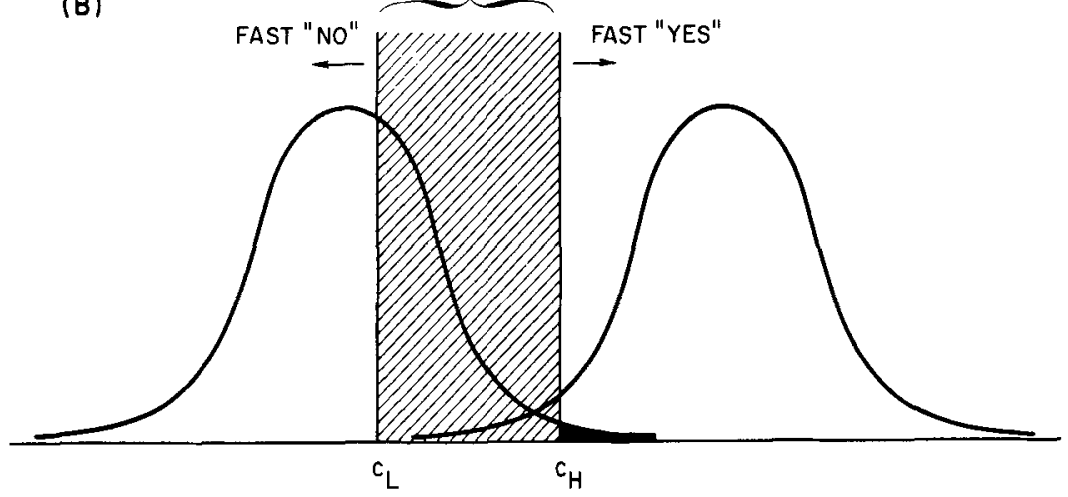

Fig. 4. Distributions of subjective familiarity values for distrator words (left) and target words (right) with means of $\mu_{\mathrm{D}}$ and $\mu_{\mathrm{T}}$, respectively, on the familiarity continuum. Figure $A$ represents the relative locations of the distributions at the start of the session, whereas Fig. B shows the increase in $\mu_{T}$ immediately after the presentation of a specific target word.

associated with it a familiarity measure that can be interpreted as a value on a continuous scale. The familiarity values associated with target words are assumed to have a mean that is greater than the mean for the distractor words, although the distributions may overlap, as shown in Fig. 4A.

In an experiment such as that done by Shepard and Teghtsoonian (1961), $S$ views a long series of items, deciding whether or not each successive item has been presented previously. In this case the subjective familiarity of the presented item leads directly to the decision to call it either "old" or "new." Stated otherwise, S has a single criterion value along the familiarity continuum which serves as a decision point for making a response. Familiarity values that fall above the criterion lead to an "old" response, whereas those below the criterion lead to a "new" response (Parks, 1966).

The present studies differ from previous recognition experiments of this type in that the target words are members of a memorized list. In this case, it is assumed that Ss can use their familiarity measure to make either a positive or negative recognition response as soon as the item is presented, or can delay their response until they have checked for the item in the stored list. If the initial familiarity value is either above a high criterion $\left(c_{H}\right)$ or below a low criterion $\left(c_{L}\right), S$ outputs a fast positive or negative response, respectively, without checking the test item against the memorized list. These responses would correspond to the areas to the right and left of the vertical lines in Fig. 4. If the subjective familiarity value associated with the presented item is of an intermediate value, $S$ will be less confident about which response to choose. Instructions emphasize minimizing errors, and consequently, in this case, $\mathbf{S}$ will check the memorized list before responding. Checking the list results in a slower response, and corresponds to the shaded area bounded between $c_{L}$ and $c_{H}$ in Fig. 4.

At the start of the experimental session there are two density functions, reflecting the probabilities of generating particular familiarity values when $\mathbf{S}$ is tested with a target or distractor word. The mean of the target distribution, $\mu_{\mathrm{T}}$, is initially separated from the mean of the distractor distribution, $\mu_{\mathrm{D}}$, by some fixed amount, as in Fig. $4 \mathrm{~A}$. The effect of the first presentation of a target word is to increase its expected familiarity rating on subsequent test trials. This is shown in Fig. 4B in which $\mu_{T}$ for previously presented target words has been increased with respect to $\mu_{\mathrm{D}}$. The area of the target distribution which falls below $c_{H}$ is thereby reduced, resulting in a lower proportion of trials on which a search through the memorized list is required.

It is possible to test some of the predictions of the model with respect to the observed latency and error data. As can be seen in Tables 1 and 2 , the latency for positive responses to the first presentation of a target word is slower than negative responses to distractors. This result is unexpected in terms of the more typical finding that positive recognition responses are faster than negatives (Hall, Sekuler, \& Cushman, 1969; Hintzman, 1969). In the present study recognition latencies are assumed to be based on a mixture of two types of responses: (1) If the retrieved information about the test word results in a familiarity rating above $c_{H}$ or below $c_{L}$, a fast positive or negative response is emitted; (2) if the judged familiarity falls between $c_{H}$ and $c_{L}$, additional time required to retrieve and scan through the memorized word list must elapse before $S$ can respond. In order to account for the fact that responses to initial presentations of target words are slower than responses to distractors, it is necessary to assume that the first presentation of a target word results in a higher probability that $\mathbf{S}$ scans through the memorized list before responding than does the presentation of a distractor word. As shown in Fig. $4 \mathrm{~A}$ this means that the area between $c_{L}$ and $c_{H}$ is more nearly centered on the target distribution than on the distractor distribution.

The effect of the location of $c_{L}$ in Fig. 4A is to limit the proportion of trials on which a distractor word is presented, and a slow search of the list follows before a negative response is made. Another effect is to include a nonnegligible portion of the target distribution (all target words with relatively low familiarity values) in the "fast no" response area. An examination of Tables 1 and 2 shows that the data support this expectation: most errors made were incorrect negative responses to initial presentations of target words. Further, since errors on target items are expected to be fast, whereas correct responses are expected to be a mixture of fast and slow responses, the 
prediction is that the average error latency will actually be faster than the average correct latency to first presentations of target items. This prediction is generally upheld. In Experiment 1 the mean overall latency of incorrect negative responses to the first tests of target words was $789 \mathrm{msec}$; a sample of correct positive responses, balanced for mean test position within the session, had a mean latency of $822 \mathrm{msec}$. The data from the first session in Experiment 2 (the second session was not included since there were too few errors) are equivocal, however, with values of 816 and $819 \mathrm{msec}$ for incorrect negative responses and correct positive responses, respectively.

It can be observed in Fig. 1 and in Table 2 that positive responses to target words on the second and all subsequent tests are much faster than responses to initial tests. This result is anticipated if the expected familiarity value of a word in the target distribution is increased following the first presentation of that word; i.e., if $\mu_{T}$ is higher on subsequent tests of target words than on the first test, as in Fig. 4B. If the same word is presented twice in succession, there is a very low probability that $S$ will search the list; therefore, a fast positive response usually will be emitted. However, if a number of tests on other words intervene between presentations of a given target word, the familiarity value associated with the second presentation of the target item will be lower than it is immediately after the word is first presented, resulting in a higher probability that $S$ will scan the memorized list before responding. In other words, $\mu_{T}$, as shown in Fig. $4 B$, gradually drifts back to its position in Fig. $4 \mathrm{~A}$ as a function of lag between tests on a given target word. The resulting increase in latency with increasing numbers of trials between consecutive tests of the same target word would thus be expected.

It was noted earlier that a linear increase in latency as a function of target list length could be taken as evidence for a search process in long-term memory similar to that hypothesized for short-term memory by Sternberg (1966). This prediction is based on the assumption that as the length of the target list increases, the number of locations that must be checked during a search of long-term memory also increases. With strings of digits as the memory sets, Sternberg obtained linear functions with identical slopes for positive and negative response latencies as functions of the number of target items in short-term memory. From this result an exhaustive scanning process was inferred; i.e., on every trial $S$ compares the test stimulus with each memorized target item and outputs a response only after all comparisons have been made.

In Experiment 1 the functions relating response time to list length are reasonably linear, but clearly are not consistent with an exhaustive scanning model. Examination of the left-hand panel of Fig. 2 (Trials 10-30) supports the exhaustive scanning model to the extent that both positive and negative slopes are approximately equal. However, for the data in the right-hand panel of Fig. 2 (Trials 64-104) the slopes are in a two-to-one relationship. This two-to-one ratio is not consistent with an exhaustive scan scheme, but would be predicted on the basis of a self-terminating scan (this prediction follows from the argument that if $S$ terminates the memory search as soon as he locates the target item, he will scan through only about half as many items on positive trials as on negative trials). It can be argued that on the early trials of the experiment $S$ exhaustively scanned his memory list, but later switched to a self-terminating search. Although this view cannot be unequivocally rejected on the basis of the data, there are difficulties with it. First, the scan rate is approximately $6 \mathrm{msec} / \mathrm{item}$, which is extremely fast compared to the typical estimate of about $40 \mathrm{msec}$ in a Sternberg-type task. Second, neither the self-terminating nor the exhaustive scanning models explain the strong lag effects shown in Fig. 3, nor do they provide an account of the fact that in the present study a substantial number of errors occur only on the first presentation of a target item.

The model proposed in the present paper offers an alternative way of looking at the data in Fig. 2. The low slope values are presumably due to the fact that $S$ does not perform a search of the memorized list on every trial but, rather, scans through the list on only those trials on which the familiarity rating of the item is of an intermediate value. When an item's familiarity value falls below $c_{L}$ or above $c_{H}$, the response is generated immediately and its latency is not dependent on the length of the target list. When the familiarity value falls between $c_{L}$ and $c_{H}$, then $S$ must scan the memorized list, and hence, on those trials, latency will depend upon list length. The obtained slopes in Fig. 2 are thus determined by three considerations: (1) the probability that an item's familiarity rating will be of an intermediate value, thereby necessitating that all or part of the target list be retrieved from memory, (2) the number of items in the retrieved list that are actually scanned, and (3) the scanning rate per item.

In terms of this model, the slope of the function relating negative response latency to list length should remain roughly constant over the experiment to the extent that the distribution of familiarity values for distractor items does not change over trials and $c_{L}$ and $c_{H}$ remain fixed; this appears to be the case if we compare the negative response functions displayed in the left and right panels of Fig. 2. In contrast, the slope of the positive response function for initial tests of target words and for subsequent tests reflects the differential search probabilities shown in Figs. $4 \mathrm{~A}$ and $4 \mathrm{~B}$. When a target word is presented for the second and third time, the lower probability of scanning the memorized list results in a smaller list-length effect than when the target word is first tested.

The model can also be used to give an account of the lag data displayed in Fig. 3. At very short intervals between tests on a given item $\mathbf{S}$ should rarely search through the memorized list, and no list-length effect should be observed. As the lag increases, however, the observed ordering of response latencies in Fig. 3 is to be expected: the probability of searching the memorized list increases as a function of lag at the same rate for the three list-length groups, but when a search does occur, its duration will depend upon the length of the target list.

In evaluating the above model or any other model against the data of Experiment 1, it is important to realize that there are two uncontrolled variables that may be accounting for some of the list-length effects. One involves the fact that the latency of a negative response to a distractor item which is in some way "related" to a target item is slower than for "unrelated" items. It is obvious that the likelihood that any given distractor word is related to one or more target words increases with the length of the target list. In effect $\mu_{\mathrm{D}}$ (and thus the mean negative response latency) can be regarded as an increasing function of the length of the target list. The other uncontrolled variable influencing list-length effects is related to the fact that positive response latencies are an increasing function of the lag between consecutive tests of a target word. Since the specific word tested on a positive trial was selected randomly from the target list in Experiment 1, the expected lag (and thus the mean positive response time) is also an increasing function of list length. Special experiments would have to be done to isolate the influence of these two variables, but it is doubtful that 
they alone could account for the list-length effects observed.

We now turn to Experiment 2 and its interpretation in terms of the proposed model. It appears that the acoustic similarity of a distractor word to a target word is not by itself an important determinant of an item's subjective familiarity value (the relatively long latencies to homophones being apparently due to visual similarities between the words of the homophone pairs); but semantic similarity has a powerful effect on the familiarity value. This result can be interpreted to mean that the subjective familiarity of a word is determined by the information retrieved about it from long-term memory, and synonyms have many stored semantic features in common. With a greater percentage of familiarity values falling above both $c_{L}$ and $c_{H}$, average response time as well as error probability should be higher for synonyms than for neutral distractors, as observed in Table 2 .

While it seems clear that semantic information is used by $S$ in determining whether or not a test item is in the target list, the cause of the effect of visual similarity on recognition latency is not entirely clear. It may be that some visual information is used in judging the familiarity of the presented stimulus, but it is also possible that visual similarity between target and distractor items leads to confusions and errors of identification before $\mathbf{S}$ can decide exactly what word is being presented.

The lack of a significant difference between repeated and unrepeated neutral distractors in Experiment 2 is somewhat unexpected. A previous exposure of a stimulus word conceivably leads to a higher subjective familiarity rating being given to that word on subsequent tests and thus should lead to a slower response time according to the model. There was some evidence that response time to a repeated distractor might be slower if the repetitions occur in close sequential proximity. However, if the presentation of a distractor word does result in a higher familiarity rating on subsequent tests, the effect is a transient one that is not comparable to the large and lasting effect apparent when target words are repeated.

\section{CONCLUSION}

In terms of the proposed model, when an item is presented on a recognition test $\mathrm{S}$ may immediately initiate a positive or negative response solely on the basis of information retrieved about the given word, i.e., its subjective familiarity value. Yet the existence of list-length effects on response latency suggests that, at least on some proportion of the trials, $\mathbf{S}$ will have to execute a more extensive search of memory, perhaps by bringing parts of the memorized list into short-term memory and using scanning processes similar to those discussed by Sternberg (1966). The probability that $S$ initiates a list-scanning process can be altered by manipulating the familiarity of the presented word. A distractor word can be made to have a relatively high familiarity value if it is in some way similar (e.g., semantically related) to a specific target word. This results in a higher expected negative response latency and error rate, as observed in Experiment 2. Attempts to manipulate familiarity by repeating test word presentations have led to somewhat surprising results. It is clear that the presentation of a target word leads to a substantial increase in its subjective familiarity value on subsequent tests. However, the repetition of distractor words apparently has no significant effect on familiarity.

By using the experimental methods described in the present paper, it is possible to examine various assumptions about how information is stored in long-term memory as well as what retrieval and search processes are employed in recovering that information. The depth and even the type of search used in recognition undoubtedly depends upon control processes selected by $S$ in order to optimize some aspect of his performance. Although definitive tests of the model proposed here cannot be made on the basis of the present data, the success of the qualitative predictions seems to justify further exploration of the basic assumptions.

\section{REFERENCES}

ATKINSON, R. C., \& SHIFFRIN, R. M.
Human memory: A proposed system and its control processes. In $\mathrm{K}$. W. Spence and J. T. Spence (Eds.), The psychology of learning and motivation: Advances in research and theory. Vol, 2. New York: Academic Press, 1968.

HALL, J., SEKULER, R.. \& CUSHMAN, W. Effects of IAR occurrence during learning on response time during subsequent recognition. Journal of Experimental Psychology, 1969, 79, 39-42.

HINTZMAN, D. Recognition time: Effects of recency, frequency, and the spacing of repetitions. Journal of Experimental Psychology, 1969, 79, 192-194.

KINTSCH, W. Memory and decision aspects of recognition learning. Psychological Review, 1967, 74, 496-504.

PAIVIO, A., YUULLE, J. C., \& MADIGAN, S. A. Concreteness, imagery, and meaningfulness values for 925 nouns. Journal of Experimental Psychology Monograph Supplement, 1968, 76, No. 1 , Part 2, 1-25.

PARKS, T, E. Signal detectability theory of recognition memory performance. Psychological Review, 1966, 73, 44-58.

SHEPARD, R. N., \& TEGHTSOONIAN, $M$ Retention of information under conditions approaching a steady state. Journal of Experimental Psychology, 1961, 62, 302-309.

SHIFFRIN, R. M., \& ATKINSON, R. C. Storage and retrieval processes in long-term memory. Psychological Review, $1969,76,179-193$.

STERNBERG, S. High-speed scanning in human memory. Science, 1966, 153, $652-654$.

THORNDIKE, E. L., \& LORGE, I. The teacher's word book of 30,000 words. New York: Bureau of Publications, Teachers College, Columbia University, 1944.

WINGFIELD, A., \& BRANCA, A. A. Strategy in high-speed memory search. Journal of Experimental Psychology, $1970,83,63-67$

YNTEMA, D. B., \& TRASK, F.P. Recall as a search process. Journal of Verbal Learning \& Verbal Behavior, 1963, 2 , 65-74.

\section{NOTES}

1. These plots were also obtained by averaging mean response latencies for each S. The results were almost identical except that all points were 20 to $40 \mathrm{msec}$ higher.

2. Synonym pairs: BOAT, SHIP: ACHE, PAIN; FIRE, FLAME; SPORT, GAME; SICK, ILL; HOUSE, HOME; LEAP, JUMP; ROCK, STONE. Homophone pairs: REIGN, RAIN; SOME, SUM; SENSE, CENTS; BOARD、BORED; PLAIN, PLANE; STAIR, STARE; PIECE, PEACE; SALE, SAIL.

3. Visually dissimilar homophones (differ in two or more letters or in length): REIGN, RAIN; SOME, SUM; SENSE, CENTS. Visually similar homophones conly two letters are different): BOARD, BORED; PLAIN, PLANE; STAIR, STARE; PIECE, PEACE; SALE, SAIL.

(Accepted for publication December 7, 1970.) 